\title{
PUFF dağı̆lım modellemesi ve hava kalitesi değerlendirmesinde kullanımı
}

\author{
Kazım Onur DEMIRARSLAN* \\ Artvin Çoruh Üniversitesi, Mühendislik Fakültesi ÇevreMühendisliği Bölümü, Artvin \\ Geliş Tarihi (Recived Date): 06.06.2017 \\ Kabul Tarihi (Accepted Date): 01.06.2018
}

\section{Özet}

Toplumların gelişimini sağlayan ve tek tek bireylere kadar yaşantılarını kolaylaştıran 21. Yüzyılın teknolojik gelişmeleri, faydacılığının yanında birçok çevre sorununu da beraberinde getirmektedir. Bu çevre sorunlarından birisi de hava kirliliğidir. Özellikle çarpık kentleşme, alt yapı eksiklikleri nedeniyle ısınmada karbon salınımı fazla olan katı yakıt kullanımı, plansız sanayileşme ile sanayi işletmelerinde filtrasyon eksikliği, hava kalitesi üzerinde kirletici etkilere neden olmakta ve hava kalitesini insanların yaşam standartlarını etkileyecek düzeye kadar düşürmektedir. Bu nedenle gerek mevcut hava kirletici kaynaklarından çıkan maddelerin dă̆glımı, gerekse yeni planlanacak sanayi, otoyol ve konutlar gibi potansiyel kirleticilerin hava kalitesi açısindan yer seçimlerinde çeşitli dağılım modelleri kullanılmaktadır. Atmosfere bırakılan kirleticiler, hava akımlarıyla uzun mesafelere; hatta kıtaları aşacak kadar dahi uzaklara taşınabilmekte, yerel hava koşullarıla veya türbülanslarla seyrelebilseler bile, kirlilik oranları yine de kabul edilebilir seviyelerin üzerinde ölçülebilmektedir. Hava akımlarıyla yayılan kirleticiler, atmosfer içerisindeki farklı ölçeklerdeki türbülanslar nedeniyle oldukça karmaşık yapıya sahiptirler. Kirletici konsantrasyonları önemli derecede, zamana göre değişiklik gösteren hava koşullarından (özellikle rüzgar, yağmur, kar, sis) etkilenmektedir. Meteorolojik olaylar kirletici dağllımlarında ana rolü teşkil etmektedir, bunun nedeni ise, kirleticilerin atmosferde seyrelme etkisinin tanımlanmasında birincil faktör olmasındandır. Dă̆llım modelleri ise atmosferde meydana gelen tüm bu olayları matematiksel yollarla hesaplayarak kirletici dă̆llımlarını kaynaktan itibaren metrelerce veya kilometrelerce uzaklıktaki konsantrasyonlarını hesaplayabilmektedir. Literatürde birçok dă̆llım yöntemi geliştirilmiş olup hepsinin birbirlerine avantaj ve dezavantajları bulunmaktadır. Sözü edilen bu dă̆llım tahmin yöntemlerinden birtanesi de PUFF dağllımdır. Yapılan bu çalışmada hava kirliliği dă̆ılım tahminlerinde sıklıkla kullanılan PUFF dă̆ılım yöntemi hakkında literatür taraması çalışması yapılmış ve bu modelleme yönteminin özellikleri hakkında Türkçe kaynak boşluğunun doldurulması hedeflenmiştir.

Anahtar Kelimeler: Dağılım, hava kalitesi, modelleme, PUFF dağılım.

\footnotetext{
* Kazım Onur DEMIRARSLAN, onurdemirarslan@artvin.edu.tr, http://orcid.org/0000-0002-1023-7584
} 


\title{
PUFF dispersion modeling and use of air quality assessment
}

\begin{abstract}
Technologies that play a role in the development of society cause many environmental problems. One of the environmental problem is air pollution. In particular, unplanned urbanization and industrialization cause a significant impact on air pollution and these factors affect the air quality levels of people's living standards. Therefore, some distribution models are used in the distribution of the material emitted existing air pollutants and also the site selection of the potential sources like new scheduled industry, highway and residential areas according to air quality. Pollutants released into the atmosphere are transported over long distances by air currents and are diluted with the local weather conditions or turbulence. Distributions by the wind are highly complex structures at different scales because of turbulence in the atmosphere. Pollutant concentrations are significantly affected the weather conditions that vary according to time (especially wind). Meteorology constitutes the main cause of pollution distribution. This reason for this, the pollutants in the atmosphere is the primary factor in defining the dilution effects. Distribution models are mathematical way to calculate with all the events occurring in the atmosphere and the concentration of pollutants sources in meters or kilometer away. Many distribution methods have been developed in the literature. These are all the advantages and disadvantages against each other. One of these mentioned distribution estimation method is PUFF distribution. In this study, literature study has been made about PUFF distribution method that the most frequently used in dispersion estimates of air pollution and it has been aimed the contribution to the limited number Turkish scientific literature about the features of this modelling method.
\end{abstract}

Keywords: Dispersion, air quality, modeling, PUFF dispersion.

\section{Giriş}

Hava, yaşam ve insan etkinlikleri üzerindeki etkisini de dikkate almak koşuluyla belirli bir zamanda atmosferin durumunu belirtmektedir ve bütün canlıların solunumuna yarayan; renksiz, kokusuz, akışkan bir gaz karışımıdır [1]. Bu kavramla birlikte, artan sanayileşme, kentleşme ve bunlara bağlı olarak sirkülasyon sağlayıcı motorlu araç trafiğgi gibi etkenler sonucunda hava kalitesi terimi de ortaya çıkmıştır. Hava kalitesi; doğadaki canlıların, insanoğlunun faaliyetlerinden olumsuz şekilde etkilenmeden yaşayabilmeleri, insanların ise sağlıklı nefes alabilmelerini, her türlü akut veya kronik akciğer rahatsızlıklarından uzak biçimde yaşamlarını sürdürmelerini sağlayan ve etrafımızı saran havakürenin sağlık açısından kabul edilebilir alt ve üst sınır değerler arasındaki kimyasal ve fiziksel özellikleri olarak tanımlanmaktadır. Ayrıca, hava kalitesi çevre üzerine etki eden hava kirliliğinin göstergesi olan, çevre havasında bulunan hava kirleticilerinin artan miktarıyla azalan bir ölçüttür [1-3]. Havayı kirleten maddeler yaşanabilir, sağlıklı hava kalitesi üzerinde etkili birçok unsurdan biridir. Hava kirliliği ise bir veya birden fazla maddenin, insan sağlığını, doğal yaşamı, şimdilik yerel habitatları etkileyebilecek, ancak böyle giderse dünya genelinde etki yaratması ne yazık ki kaçınılmaz olan; cansız varlıkların bile yapısını etkileyebilecek düzeyde kimyasal 
maddenin, atmosferde doğal olarak bulunan konsantrasyonundan daha fazla miktarda bulunması olarak tanımlanabilir [4]. Soluduğumuz hava içerisindeki gaz, buhar, toz, koku zerrecikleri gibi istenmeyen serbest radikallerin sağlısız bir şekilde artması sonucunda, insan ve hayvan sağlığında bozulmalar ile bitkilerde de hasarlar meydana gelebilmektedir [5]. Tüm bu etkenlere neden olan hava kirleticileri bir çok kaynaktan yayılmaktadır ve bunlardan en önemlisi olan insan kaynaklı hava kirleticilerinin kaynakları, yanma, taşıma, endüstriyel prosesler ve katı atık tesisleri olarak sayılabilmektedir [6].

Son elli yıl içerisinde dünyanın nüfus artış hızının artması (\%2,7 kişi/yıl) ve insanlık tarihinin ilk zamanlarına nazaran ilk defa kentsel ve endüstriyel alanların kırsal alanlardan daha fazla olması birçok çevre sorunlarını beraberinde getirmiştir. Bu çevre sorunlarından yalnızca bir tanesi olan kentlerdeki düşük hava kalitesi, akut ve kronik rahatsızlıklara neden olmakta ve etkileri, hava kirleticilerinin konsantrasyonları ile maruziyet süresi gibi faktörler sonucunda artmaktadır. Bu durum ise kentsel alanlar üzerinde değişkenlik gösteren atmosferik koşullara, kirleticilere ve yüzlerce kilometreye kadar olabilen yayılım süreçleriyle de yakından ilgili olmaktadır [7-9].

Hava kirleticilerinin uzak mesafelere taşınımı hava kalitesinin belirlenmesinde oldukça önemlidir. Hava kalitesi ölçümlerinin yapılamadığı noktalarda modelleme çalışmaları yapılarak o bölgelerdeki kirlilik hakkında oldukça önemli bilgiler edinilebilmektedir. $\mathrm{Bu}$ nedenle birçok hava kalitesi modelleme tekniği bulunmakta ve kullanılmaktadır. Kullanılan modellemeler içerisinde en çok tercih edilenlerden birtanesi de PUFF dağılım modeli olmaktadır. Yapılan bu çalışmada hava kirliliği dağılım tahminlerinde sıklıkla kullanılan PUFF dağılım yöntemi hakkında literatür tarama çalışması yapılmış ve bu modelleme yönteminin özellikleri hakkında Türkçe kaynak boşluğunun doldurulması hedeflenmiştir.

\section{Kirleticilerin atmosferdeki davranışları}

Hava kalitesini azaltan kirleticilerin atmosfer içerisindeki yayılım karakteri, kirletici partiküllerin niteliğinin yanında, meteorolojik olaylar ve atmosferin dinamik yapısından da önemli derecede etkilenmektedir. Bir kaynaktan çıkan kirleticilerin atmosferdeki dağılımları, rüzgâr hızı ve yönü, sıcaklık, güneş 1şı̆̆ı oranı, bulutluluk, atmosferik türbülans, inversiyon katmanı, karışım yüksekliği ve yağışlılık ve nem gibi meteorolojik koşullara bağlı olarak değişkenlik göstermektedir. Bu atmosferik etkiler, atmosferde görülen fiziksel kanunlardan ve olaylardan oluşmaktadır. Atmosferdeki fiziksel durumlar taşınımı ve dağılımı kolaylaştırmakta veya kısıtlamaktadır. Rüzgâra bağlı uzaklık incelendiğinde, gazların deşarj noktasından gidebileceği en uzak mesafenin, kirletici gazların atmosfer içerisindeki maksimum çözünürlüğüne bağlı olarak değiştiği görülmektedir. Bu durumun sonucu olarak da kaynaktan ne kadar çok uzaklaşılırsa, yer seviyesindeki kirletici konsantrasyonu da azalmaktadır. Hâkim rüzgâr yönü, duman bulutu akımının yönünü de belirlemektedir. Rüzgârın hızı duman bulutu akımına etki etmektedir. Hızlı bir rüzgârda duman bulutu akımı da hızlı olacaktır. Ayrıca seyrelme oranı da artacaktır [10-12].

Örneğin yer seviyesinden veya yüksek bir kaynaktan (örneğin baca) yayılan bir kirletici, ani şekilde atmosferik işleme maruz kalmaktadır ve dikey-yatay taşınıma uğrarken gittikçe artan bir şekilde dağılma eğilimi göstermektedir. Taşınım, gaz ve partiküllerin 
hava hareketleri ile bir yerden başka bir yere gitmesi olarak tanımlanabilir ve farklı kaynaklardan gelen, birbirleri ile etkileşen kirleticiler için bir dağılım ve seyrelme ortamı sağlamaktadır [11].

Atmosfer, yapı olarak kararsız olup, değişkenlik gösterebilir. Kararsız olduğu durumlarda atmosferin üst katmanlarına doğru birçok karışım görülür ve bu durum özellikle güçlü güneş ışığının ve rüzgârın olduğu zamanlarda meydana gelir. Böyle bir koşul oluştuğunda kirleticiler daha hızlı yayılmakta, Geceleri ise daha kararlı bir yapı sergilemektedir. Bunun sonucu olarak da kirleticilerin yayılımı yavaşlamaktadır [13].

Atmosferdeki kirleticilerin dağılımına etki eden faktörlerden biri de karışım yüksekliğidir. Karışım yüksekliği terimi yeryüzü üzerindeki hava hacminin dikey yüksekliğinde meydana gelen ve göreceli olarak güçlü bir karışımın olduğu yüksekliktir ve bu alanda kirleticilerin yoğunluğunda artış görülmektedir. Karışım yüksekliğinin doğal ve kararsız durumlar altında görüldüğü farz edilmektedir. Karışım yüksekliği günlük veya mevsimsel olarak farklılık göstermekte olup; yeryüzü topoğrafyasından ve yüksek basınç sistemlerinden belirgin bir şekilde etkilenmektedir. Gün içerisinde güneş doğumundan önce minimum karışım yüksekliği görülmekte, saat ilerledikçe güneşten gelen ısının artmasıyla karışım yüksekliği oranı da artmaktadır. Maksimum değeri ise yaz aylarında öğleden sonranın ilk saatlerinde gözlenmektedir (sık olarak birkaç bin metrede). Minimum seviyesi de sonbaharın sonları ve kışın kuzey yarımküre ile orta enlemlerde görülmektedir [11]. Karışım yüksekliği emisyonların dağılımında kritik bir role sahiptir. Tipik olarak kış ayları yaz aylarından daha kirli olmaktadır. Bunun sebebi kış ayları boyunca karışım yüksekliği seviyesinin düşük olmasıdır. Matematiksel olarak konsantrasyon kütle/hacim olarak tanımlanmaktadır. Bir kentsel çevrede emisyonların, eşit olarak karıştığı, düşük karışım yüksekliğinde yüksek ortam konsantrasyonlarında olduğu farz edilmektedir [14].

Atmosferik sınır katmanı ise kirleticilerin yoğunluklarının değiştiği, meteorolojik koşulların hüküm sürdügü, troposferin küçük bir kısmıdır. Kirleticilerin dağılımı ise iki farklı işlem sonucunda meydana gelmektedir:

- Uzun ömürlü kirleticilerin uzak mesafelere taşınımını açıklayan, rüzgâr alanlarının oluşturduğu yatay taşınım,

- Sınır katmanı efekti sonucu atmosferik türbülansların meydana getirdiği dikey karışım [15].

\section{Hava kalitesi dağılım modelleri}

Zayıf hava kalitesinin insan sağlı̆̆ üzerindeki olumsuz etkileri uzun zamandan beri bilinmesine rağmen her zaman gözardı edilmiş ve hep ikinci planda algılanabilecek bir kirlilik olarak algılanması istenmiştir. Dünya sağlık örgütünün tahminlerine göre kentsel hava kirliliğinin insan ömrünü kısalttığı ve her yıl Avrupa'daki ölümlerden 800 bininden ve ABD'deki y1llık ölümlerin \%2-3 ünden sorumlu olduğu tahmin edilmektedir. Birçok çalışma, özellikle hava şartlarının ve lokasyonun günlük hava kalitesinin belirlenebilmesinde önemli bir role sahip olduğunu göstermiştir. Sicaklık ve gün 1şığ1 (veya bulutluluk), $\mathrm{NO}_{\mathrm{x}}$ ve VOC'lerden yüzey ozonu oluşumundaki fotokimyasal reaksiyonların verimliliğinde önemli bir etkendir. Rüzgâr hızı, kirleticilerin bölgeden uzaklaşmasında, rüzgâr yönü ise kirleticilerin hangi noktaya 
yönelmesi üzerinde etkilidir. Kirletici alanı üzerindeki antisiklonik koşullar sıklıkla alçak basınç inversiyonunu tetiklemekte ve bu da kirleticilerin dikey yöndeki hareketini belirlemektedir. Bu durumda ise yüzeye yakın sağlıksız hava beraberinde gelmektedir. Nem koşulları da ikincil kirleticilerin dönüşümünde veya kuru ve yaş birikiminde özellikle etkili olmaktadır [16].

Anlatılan tüm bu durumlar kirleticilerin atmosfer içersindeki davranışlarında etkilidir ve bilinen bu koşullar kirletici hareketlerinin hesaplanmasında önemli verilerdir. Sonuç olarak hava kalitesi modelleri, emisyonların, meteorolojinin, atmosferik konsantrasyonların, birikimin ve diğer faktörlerin arasındaki ilişkilerin belirlendiği sayısal araçlar olarak tanımlanır. Hava kalitesi modelleme hesaplamaları ile hava kalitesinin birebir gerçek ölçümü arasında her zaman farklılıklar bulunmaktadır. Özellikle hava kirliliği ölçümleri, ortam konsantrasyonları ve birikim hakkında önemli kantitatif bilgiler vermesine karşın, sadece hava kalitesi probleminin nedenini tanımlayamadan, belirli bir alanda ve zamandaki hava kalitesini göstermektedir [17]. Hava kalitesi modellemesinin değerlendirilmesi, geçtiğimiz yıllarda artan bir şekilde kullanılmaya başlanmıştır. Bundan yaklaşık 10 yıl önce yapılan modellemeler aylarla ifade edilebilecek uzunlukta hesaplamalarla yapabilen sınırlı çalışmalar iken günümüzde bilgisayar teknoloji ilerleyip kapasiteleri arttıkça modellerin kabiliyetleri de orantılı olarak artmıştır [18].

Daha önceden de açıklandığı üzere; atmosferik dağılım, topoğrafyaya, arazi kullanımına, meteorolojiye ve emisyonlara bağlıdır. Bu veriler havadaki kirlilik konsantrasyonlarının karmaşık tahmininde ve hava kalitesi modellerinde sistematik olarak kullanılan karmaşık bir prosestir. Kullanılan modelleme yöntemleri karmaşık olmasına rağmen, elde edilen sonuçların kesinliği ve doğruluğu, bu modellerde kullanılan emisyon envanterine bağlı olarak azalmaktadır [19].

Yukarıda yapılan açıklamaların sonucunda dağılım modeli kavramı, salınan kirletici konsantrasyonları için bilimsel prensiplere dayanan matematiksel veya fiziksel süreçlerin ilişkileri olarak özetlenebilir ve modelleme sonuçları ile çalışma alanının hava kalitesi hakkında bilgi sahibi olunabilir. Ayrıca yeni kurulacak bir fabrikanın yer seçiminde ve baca tasarımının yapılmasında, filtrasyon sisteminin tesisinde yardımcı olmaktadır. Bunun yanında emisyon kaynağından en çok etkilenebilecek alanların izlenmesinde ve buralara farklı senaryoların uygulanmasında da kullanılabilmektedir. Dağılım modellerinde emisyon oranı bilgisine, meteorolojik ve topoğrafya verilerine ihtiyaç vardır [20] ve dağılım sürecini anlayabilmek için iki durum bulunmaktadır:

- Atmosferde yayılan kirleticilerin konsantrasyonları her zaman azalma eğilimi göstermektedir. Konsantrasyon asla ilk yayıldığı konsantrasyondan büyük olamaz,

- Yayılan duman en sonunda atmosfer ile aynı momentuma sahip olacaktır (örneğin hareketin yönü ve hızı). Böylece duman yayıldığında karışım süreci momentum ve bileşenlerin karışımını barındıracaktır [21].

Dağılım, atmosfer içerisinde salınan kirleticilerin seyrelmesini ve taşınımını içermektedir. Dağılım modelleri ise bir kaynaktan çıkan kirleticilerin atmosferik süreçlerini matematiksel formülasyonlarla karakterize etmektedirler. Uzun mesafeli atmosferik dağılım modelleri, bölgesel ve kıtasal ölçeklerde, saat ve günlerle ölçülebilecek düzeyde konsantrasyonları hesaplayabilmektedirler [22]. Kirleticilerin dağılım ve taşınımına birçok faktör etki etmektedir ve bunları matematiksel modellemeler olmaksızın açıklayabilmek mümkün olamamaktadır. Atmosferik 
kirleticilerin modellemesinde kullanılan birbirinden farklı birçok matematiksel modelleme vardır ve bu modeller söz konusu amaçlarda kullanılabilmektedir [23]. Modelleme teknolojisi dağılım ve seyrelme davranışlarının analizi için kullanışlı ve ekonomik bir yöntemdir. Dağılım hesaplamalarında kullanılan birçok model bulunmaktadır. Örneğin, plume modelleme rüzgarın olduğu koşullarda, kararlı hallerde, kirletici dağılımını hesaplayabilmektedir. Bir diğer yaklaşım ise Puff modellemedir, bu modelleme sistemi ise rüzgarsız sakin koşullarda kullanılmaktadır [24]. Puff modeller karmaşı arazi yapısı üzerindeki atmosfer içerisindeki dağılımları konusunda oldukça etkili olmaktadır. Bu modellerin pratikliği ve teorik basitliği ile esnekliği kirletici dağılımında bu modelleri başarılı hale getirmiştir. İlk puff modellerin kirletici dağılımlarında Gauss formülasyonunu kullandığı literatürde görülmekte ancak son yıllarda ise farklı formülasyonların ortaya çıktığı bilinmektedir [23].

Hava kirliliği dağılım modellemeleri uygulanırken, hava kirleticilerinin atmosfer içerisinde dağılımının nasıl olduğu, matematiksel olarak tahmin edilebilmektedir. Burada yapılan işlem, geliştirilen bilgisayar programları ile kirleticilerin matematiksel eşitliklerinin ve algoritmaların çözülmesidir [25].

\section{Puff dağılım modellemesi}

PUFF modeller, homojen ve kararlı olmayan atmosferik sınır katmanındaki, zamana bağlı emisyon dağılımının açıklanmasında kullanılmaktadırlar. En çok kullanılanı ise Gauss tabanlı PUFF modelleridir. Gauss modeller teorik olarak kesinliğe dayanan ancak atmosferdeki dağılım ve taşınımı gerçek anlamda çözememektedir. Çözüm ise sigma olarak adlandırılan ampirik parametreler vasitasıyla yapılmaktadır. PUFF modellemeler homojen ve kararlı olmayan meteorolojik ve emisyon koşullarında kirleticilerin davranışlarının modellenmesinde kullanılmaktadırlar. Emisyonlar PUFF denilen hücrelere ayrılmıştır ve her bir hücrenin rüzgâra göre değişkenliği hesaplanmaktadır (Bkz. Şekil 1) [26]. PUFF modelleme tekniği, akım yönündeki dağılımın hesaplanmasını, düşük rüzgâr hızlarında da yapabilmektedir. Basit analitik puff modeli kararlı ve kararsız durumlar için formüle edilmiştir. Yaygın olarak Gauss Plume modeli gibi birçok analitik dağılım modelleri akım yönündeki seyrelmede ortalama adveksionu ihmal etmekte bundan dolayı konsantrasyon modellemelerinde ortalama rüzgar hızı sıfırdır yaklaşımı olarak tekli davranışı kullanmaktadır. Sonuç olarak $2 \mathrm{~m} / \mathrm{s}$ den düşük rüzgâr hızlarında modellemede hatalar oluşmaktadır. PUFF modelleme yaklaşımı akım yönündeki dağılım ve sakin koşullar ile düşük rüzgâr durumlarını hesaplama yeteneğine sahiptir [27].

PUFF modelleme kirleticileri çok sayıda kirletici paketi olarak ele almaktadır. Birçok PUFF modeli kirleticileri her bir alıcı noktasında zamanı dondurmuş bir şekilde ele alarak hesaplamaktadır yani her bir PUFF hücresi belirli bir zamanda (örnekleme aralığı) donmuş bir şekilde hesaplanmaktadır. Daha sonra bir diğer örnekleme zamanına kadar kirletici madde hareketine devam etmektedir. Her bir alıcı noktasındaki PUFF hücrelerinin toplam katkısı hesaplanmaktadır. Uygulama ve modele bağlı olarak bu örnekleme aralığı bir saatlik süreden başlamaktadır [28].

PUFF modellerin algoritmaları ise 5 temel adımda yapılmaktadır [29]:

1-) Emisyon: Bir puff her bir emisyonun çıkış noktasında üretilmektedir, 
2-) Adveksiyon: Her bir PUFF hücresinin merkezi yerel rüzgarlara göre hareket etmektedir,

3-) Difüzyon: Tüm PUFF hücreleri yerel türbülans koşullarına göre artmaktadır,

4-) Kuru ve Yaș Birikim, Kimyasal Bozunma: Her bir PUFF hücresi, bu koşullar altında azalmaktadır ve bu etkiler hesaba katılır.

5-) Alıcı Noktalarının Katkısı: Her bir alıcı noktasındaki katkı, mevcut PUFF hücrelerinin toplamının hesaplanmasıyla bulunur.

PUFF dağılımın şematik gösterimi Şekil 1 de verilmektedir:

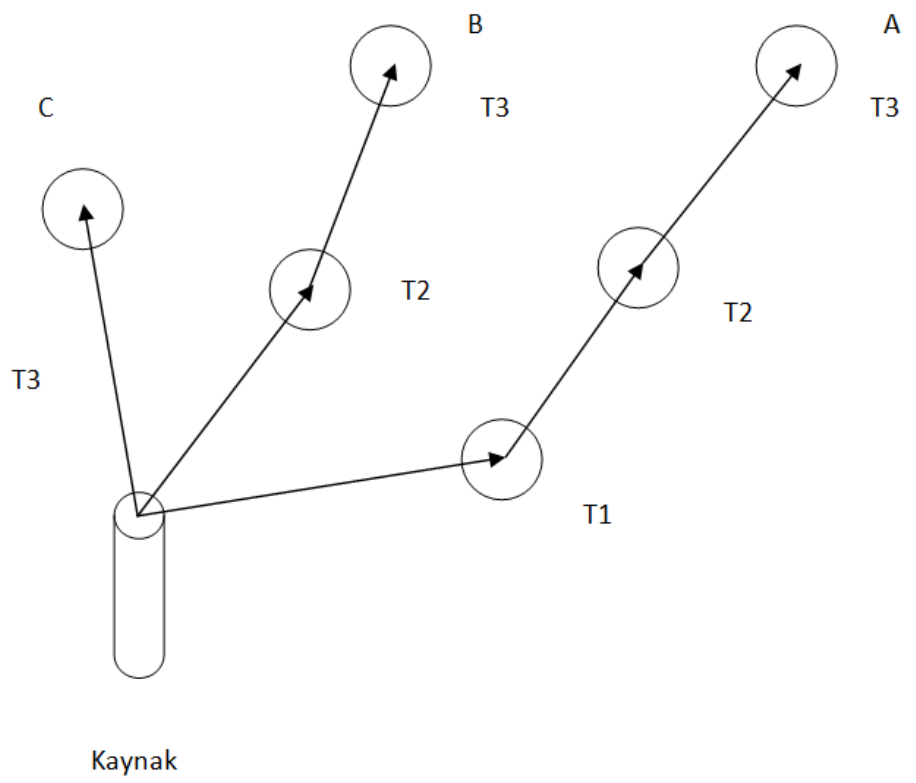

Şekil 1. PUFF dağılımın şematik gösterimi [30].

Şekil 1 deki A, B ve C PUFF hücreleri sırasıyla T1, T2 ve T3 zamanında oluşmuşlardır. Her bir PUFF hücresi kendi gauss dağılımına göre yayılmaktadırlar.

\subsection{Gauss PUFF karakteristikleri}

Her bir PUFF hücresindeki konsantrasyon dağılımı, üç boyutlu fiziksel ortamdaki Gauss yaklaşımıdır. Üç yöndeki PUFF hücrelerinin ölçeklerinin standart sapmaları ve her bir hücre merkezinin konumu ortalama olarak ifade edilmektedir. Uygunluk nedeniyle rüzgar yönündeki $\sigma_{\mathrm{x}}$ standart sapma çapraz rüzgardaki $\sigma_{\mathrm{y}}$ standart sapmaya eşitlenir ve $\sigma_{x y}$ olarak ifade edilir. Puff hücresinin aktivitesinin devamlı olduğu farz edilir, böylelikle de birikim ve dönüşümler modellenmez [31].

Gauss PUFF formülü ise aşağıdaki gibidir:

$C=\left(\frac{Q_{t}}{2^{\frac{1}{2}} \pi^{\frac{3}{2}} \sigma_{x} \sigma_{y} \sigma_{z}}\right) \exp \left(-\frac{\left(x-x_{0}\right)^{2}}{2 \sigma_{x}^{2}}\right) \exp \left(-\frac{\left(y-y_{0}\right)^{2}}{2 \sigma_{y}^{2}}\right) \exp \left(-\frac{h_{e}^{2}}{2 \sigma_{z}^{2}}\right)$

Burada,

Her bir gauss PUFF hücresi zamana göre farklılık gösteren beş yönlü parametreyle ifade edilir.

$\left[\mathrm{x}, \mathrm{y}, \mathrm{z}, \sigma \mathrm{xy}, \sigma_{\mathrm{z}}\right]$

Burada; 


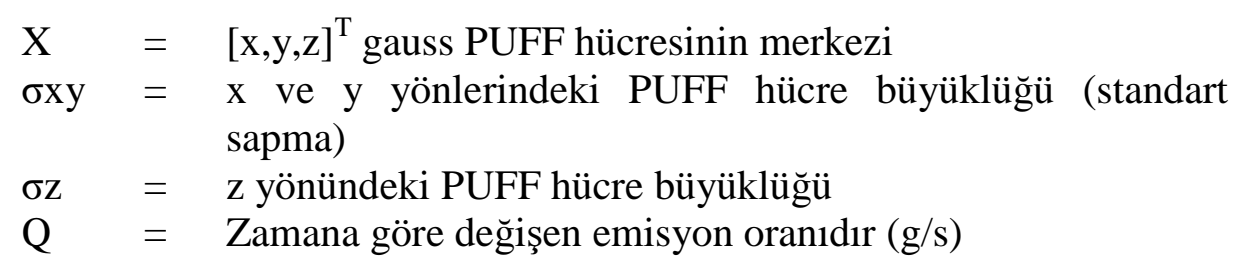

\subsection{Lagrangian Puff modeller}

Geliştirilmiş modeller; partikül, PUFF ve grid modeller olmak üzere üç kategoride incelenmektedir. PUFF modeller yaygın olarak kullanılan geliştirilmiş modellerdendir. Bunun nedeni gerçek meteorolojik koşullar ile birçok durumda en verimli şekilde hesaplama yapılabilmesidir. PUFF modeller üç boyutlu meteorolojik veriler kullanmasına karşın ISCST-3 gibi diğer modellerinde kullanıldı̆̆ yüzeysel gözlemlere dayanan meteorolojik verileri de kullanabilirler [32].

Lagrangian PUFF formülü aşağıdaki gibi ifade edilmektedir [32].

$$
\begin{aligned}
& C(x, y, z)=\frac{Q_{i p}}{(2 \pi)^{1,5} \sigma_{x} \sigma_{y} \sigma_{x}} \exp \left[-0,5\left(\frac{x}{\sigma_{x}}\right)^{2}-0,5\left(\frac{y}{\sigma_{y}}\right)^{2}\right]\left\{\exp \left[-0,5\left(\frac{z-H}{\sigma_{z}}\right)^{2}\right]+\right. \\
& \exp \left[\operatorname{xp}\left[-0,5\left(\frac{z+H}{\sigma_{z}}\right)^{2}\right]\right\}
\end{aligned}
$$

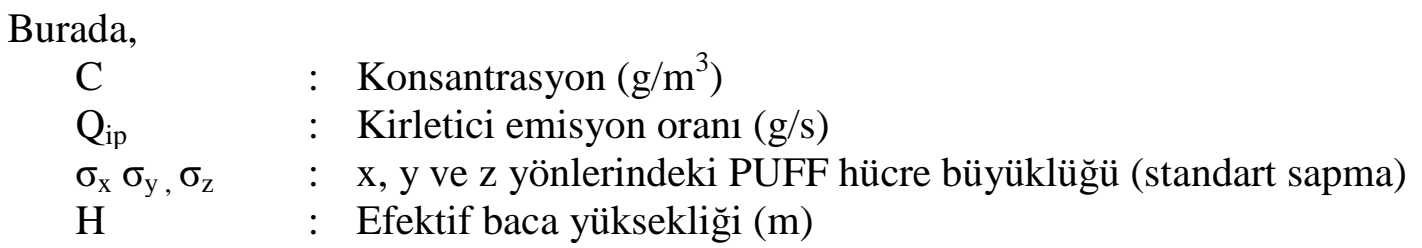

PUFF modellemeler zamana bağımlı olup eksensel dağılımı göz önünde bulundurmaktadır. Ancak gerçek hava koşullarını en iyi şekilde temsil etmelerine karşın, Plume modellemeleriyle karşılaş̧ırıldığında hala birkaç hataya sahiptirler. Örneğin plume modellemelerinin hava verilerini işlemesi daha zordur. PUFF modellemeler, meteorolojik koşulların veya arazinin çok karmaşık olması halinde ve/veya çok düşük rüzgar hızlarının hakim olduğu alanlarda kullanılması önerilmektedir [32].

\subsection{Literatürde bulunan çalışmalar}

Literatürde PUFF dağılım modellemesi kullanılarak yapılan birçok çalışma bulunmaktadır. $\mathrm{Bu}$ çalışmalardan bir kısmı incelendiğinde, Demirarslan ve Doğruparmak (2016) tarafından yapılan çalışmada, Kocaeli ili Körfez ilçesindeki Noktasal ve Alansal kaynaklardan yayılan CO ve NOx kirleticilerinin dağılım tahminleri için kararlı hal Plume modelleri (AERMOD, ISCST-3) ile Langrangian Puff modeli (CALPUFF) kullanılmıştır. Ölçüm sonuçları ile model sonuçlarının istatistiksel olarak karşılaştırılması sonucunda NOx kirleticisi için doğruluk oranı ISCST-3 > CALPUFF> AERMOD CO kirleticisi için CALPUFF > AERMOD >ISCST-3 olarak bulunmuştur [33]. Yine Demirarslan vd. tarafından (2017) yine Kocaeli ili Körfez ilçesi için yapılan çalışmada Noktasal ve Alansal kaynaklardan yayılan $\mathrm{SO}_{2}$ ve PM10 kirleticilerinin dağılımları incelenmiștir. Dağılımlar kararlı hal Plume modelleri (AERMOD, ISCST-3) ile Langrangian Puff modeli (CALPUFF) kullanılarak yapılmışıır. Çalışma alanında yapılmış olan ölçümler ile modelleme sonuçları istatistiksel olarak karş̧laştırıldıklarında $\mathrm{SO}_{2}$ kirleticisi için doğruluk oranı ISCST-3 >CALPUFF > AERMOD, PM10 kirleticisi için ise CALPUFF > AERMOD > ISCST-3 olarak bulunmuştur [34]. Joneidi vd. (2018) tarafından Tahran (İran)'da yapılan 
çalışmada çizgisel kaynaklardan yayılan $\mathrm{CO}$ ve $\mathrm{SO}_{2}$ kirleticilerinin dağılımları CALPUFF modeli yardımıyla tahmin edilmiştir. Alanda yapılan ölçüm sonuçları ile model sonuçlarının karşılaştırılmasında model sonuçlarının ölçümlerden daha az olduğu belirtilmiştir. Buna neden olarak ise ölçüm sonuçları ile meteorolojik verilerin kesinliğinin olmaması gösterilmiştir. Ayrıca çalışmada farklı istasyonlardan alınan meteorolojik verilerin kullanılması ile ölçümlere daha yakın sonuçların çıkabileceği belirtilmiştir [35]. Sagan ve arkadaşları tarafından yapılan çalışmada ise Peru La Oraya şehrinde alansal ve noktasal kaynaklardan meydana gelen $\mathrm{SO}_{2}$ emisyonları CALPUFF modelleme sistemi ile hesaplanmıştır. Modelleme sonucu elde edilen veriler ölçüm sonuçları ile karşılaştırılmış ve uyumlu oldukları belirtilmiştir [36]. Leone vd. (2016) tarafından İtalya Caserta'da çimento fabrikasından meydana gelen PM10 emisyonlarının dağılımları Langrangian Puff dağılım modeli olan SCIPUFF (Secondorder Closure Integrated Puff) ile hesaplanmıştır. Model sonuçları üç farklı yerde yapılan ölçüm sonuçları ile farklı istatistiksel yöntemler kullanılarak karşılaştırılmış ve birbirleri ile tutarlı oldukları belirtilmiştir [37]. Connan vd. tarafından yapılan bir çalışmada Kuzey Batı Fransa' da bulunan nükleer madde yeniden işleme tesisine 18-50 $\mathrm{km}$ mesafelerde alınmış olan ${ }^{85} \mathrm{Kr}$ örnekleri ile model sonuçları karşılaştırılmıştır. Modelleme çalışmasında bir tanesi Puff dağılım modellemesi olan RIMPUFF ile ADMS ve HYSPLIT olmak üzere toplam üç model kullanılmıştır. Çalışma sonuçlarına göre RIMPUFF modelinin diğerlerine göre daha iyi sonuç verdiği belirtilmiştir [38].

\section{Sonuç}

Hava kalitesi değerlendirmesinde modelleme programlarının kullanımı bilgisayar teknolojilerinin gelişmesi sayesinde günümüzde oldukça yaygınlaşmıştır. Hava kalitesinin birebir ölçülmesinin zorlukları olarak, ölçüm cihazlarının maliyetleri, karmaşık kullanım yöntemleri, her nekadar elektronik veri işleme cihazları olsa da belli bir bilgi ve eğitim gerektirmeleri ile uygun ölçüm noktalarının ise mesleki tecrübeye dayalı olarak belirlenmesinin önem arzetmesi sayılabilmektedir. Bunun yanında, belirli bir çalışma alanında bulunan kirleticilerin ölçümünün çalışma alanının her noktasında yapılması teoride mümkün gibi gözükse de; pratik uygulamalarının son derece zor ve masraflı olması, mesleki tecrübeyi teknolojik ekipmanların önünde tutmaktadır. Ayrıca ölçümleri haritaya işlemek, eldeki sayısal verileri görselleştirmek, dijital ortamda kaydetmek ayrı bir iş yükü oluşturmaktadır.

Kurulması planlanan sanayi tesisinin veya bir katı atık depolama tesisinin hava kalitesi üzerine etkilerini incelemek, ardından insan ve çevre sağlığını etkilemeyecek yer seçimini yapmak da ; hava kalitesi modelleme sistemleri ile yapılmaktadır. Doğal olarak kullanılan tüm modelleme sistemleri kesin ve doğru sonuçlar verememekle birlikte mesleki tecrübe ve doğanın uyumluluk beklentisi içinde olduğu düşüncesi ile hareket ederek yer seçimlerinde mesleki önseziler ile modellemelerin birleştiği yerler tercih edilmelidir. Bunun nedeni olarak da hesaplama yöntemleri, kullanılan kirletici envanterinin doğruluğu, çalışma alanının topoğrafik yapısının gerçeği yansıtamaması, elde edilen meteorolojik verilerin eksik ya da hatalı olması sayılabilir. Modelleme programlarının istenmeyen bir diğer özelliği de doğru sonuçların alınabilmesi için giriş verilerinin arttırılmasıdır bu durum ise modelleme programlarının kullanımını zorlaştırmaktadır. Ancak gelişen teknoloji ve artan bilgi birikimlerinin sonucu olarak modelleme programları da gelişmekte ve daha güvenilir sonuçlar veren sistemler olarak kullanıcıya sunulmaktadır. 
Modelleme sistemleri sadece bilimsel çalışmalarda veya herhangi bir kaynaktan yayılan kirletici dağılımlarında kullanılmamaktadır. Özellikle gelişmiş ülkelerdeki hava kalite standartlarının belirlenmesinde kanun koyucular tarafından modelleme sistemlerinin yardımına başvurulmakta ve sınır değerler buna göre belirlenmektedir. Ülkemizde ise kurulması planlanan bazı işletmelerin (örneğin termik santraller, maden arama çalışmaları gibi) ÇED (Çevresel Etki Değerlendirmesi) raporlarında hava kalitesi üzerindeki etkilerini gösteren modelleme haritaları istenmektedir. Buna benzer olarak bu haritalar mahkemeler tarafından bilirkişi raporlarına da konu olabilmektedir.

Sonuç olarak modelleme sistemlerinin önemi, kullanımı ve güvenilirliği gelecek yıllarda daha da artacak, istenilen alan ve mesafedeki hava kalitesine ait ölçümlere ihtiyaç duyulmadan kesin fikir sahibi olunabilecektir.

\section{Kaynaklar}

[1] Kaya, D., Öztürk, H.H., Hava Kalitesi Yönetimi, Umuttepe Yayınları, 1. Bask1, Kocaeli, (2013).

[2] URL-1, http://www.bcairquality.ca/101/what-is-air-quality.html, (08.06.2009).

[3] URL-2, http://www.doncaster.gov.uk/airq/what_is_air_quality/what_is_air_quality.asp, (08.06.2009).

[4] Sofuoğlu, A., Sofuoğlu, S.C., Editör: Çınar Ö., Çevre Kirliliği ve Kontrolü, Nobel Yayınları, 1. Baskı, Ankara, (2008).

[5] URL-3, http://www.epa.vic.gov.au/air/aq4kids/pollution.asp (08.06.2009).

[6] Vesilind, P.A., Morgan, S.M., Introduction to Environmental Engineering, Thomson Brooks/Cole, 2nd.Edt. USA, (2004).

[7] Singh, K.P., Gupta, S., Rai, P., Identifying Pollution Sources and Predicting Urban Air Quality Using Ensemble Learning Methods, Atmospheric Environment, 80, 426-437, (2013).

[8] Parrish, D.D., Singh, H.B., Molina, L., Madronich, S., Air Quality Progress in North American Megacities: A Review, Atmospheric Environment, 45, 39, 7015-7025, 2011.

[9] Giannouli, M., Kalognomou, E.A., Mellios, G., Moussipoulos, N., Samaras, Z., Fiala, J., Impact of European Emission Control Strategies on Urban and Local Air Quality, Atmospheric Environment, 45, 27, 4753-4762, (2011).

[10] URL-4, http://www.ess.co.at/AIRWARE, (08.06.2009).

[11] Dodish T., Air Quality,4th ed., Lewis Publisher, Indiana, (2003).

[12] Helmis, C.G., Sgounos, G., Flocas, H., et. al., The Role of Meteorology on the Background Air Quality at the Athens International Airport, Atmospheric Environment, 45, 35, 5561-5571, (2011).

[13] URL-5, http://www.environment-agency.gov.uk, (11.12.2010).

[14] Guttikunda, S.K., Jawahar, P., Aplication of SIM-Air Modelling Tools to Assess Air Quality in Indian Cities, Atmospheric Environment, 65, 551-561, (2012). 
[15] Sportisse B., Fundamentals in Air Pollution from Processes to Modelling, 1st ed., Springer, London, (2008).

[16] Lee, C., Ballinger, T., Domino, N., Utilizing Map Pattern Classification and Surface Weather Typing to Relate Climate to Air Quality Index in Clevland, Ohio, Atmospheric Environment, 63, 50-59, (2012).

[17] Daly, A., Zannetti, P., Air Polluiton Modelling-An Overview, Ambient Air Pollution, 1, I(2003), 15-28, (2007).

[18] Eder, B., Bash, J., Foley, K., Pleim, J., Incorporating Principal Component Analysis Into Air Quality Model Evaluation, Atmospheric Environment, 82, 307-315, (2014).

[19] Coelho, M.C., Fontes, T., Bandeira, J.M., Pereina, S.R., et al., Assessment of Potantial Improvements on Regional Air Quality Modelling Related with Implementation of a Detailed Methodology for Traffic Emission Estimation, The Science of the Total Environment, 470-471, 127-137, (2014)

[20] URL-6, http://environment.alberta.ca, (11.12.2010).

[21] Erbes R.E., A Practical Guide to Air Quality Compliance, 2nd ed., John Wiley \& Sons Inc., New York, (1996).

[22] [22] Konda, U. Singh, T. Singla, P. Scott P., Uncertainıty Propagation In PuffBased Dispersion Models Using Polynomial Chaos, Environmental Modelling and Software, 1-11, (2010).

[23] Silva E.J.G., Tirabassi T., Vilhena M.T., Buske D., Quadros R.S., Solution of the Puff Model for Pollutant Dispersion in the Atmospheric Boundary Layer by the Giltt Method, 22nd International Congress of Mechanical Engineering, November 3-7 Brazil, P:10384-10391, (2013).

[24] Mori, A., Integration of Plume and Puff Difussion Models/ Application of CFD. Atmospheric Environment, 34, 45-49, (2000).

[25] URL-7, http://www.epa.gov/ttn/scram/aqmindex.htm, (25.08.2012).

[26] Pereira L.L., Costa C.P., Vilhena M.T., Tirabassi T. Puff Models for Simulation of Fugutive Hazardous Emissions in Atmosphere, Journal of Environmental Protection, 2, 154-161, (2011).

[27] Luhar, A.K., Analytical Puff Modelling of Light-Wind Dispersion in Stable and Unstable Conditions, Atmospheric Environment, 45, 2, 357-368, (2011).

[28] Scire, J.S., Strimaitis, D.G., Yamartino, R.J. A User's Guide for the Calpuff Dispersion Model, Earth Tech. Inc. (2000).

[29] Zannetti, P., A New Gaussian Puff Algorithm for Non-Homogeneous, NonStationary Dispersion in Complex Terrain, Air Pollution Modeling and Its Application I NATO-Challenges of Modern Society Volume 1, S 537-549, (1981)

[30] Jung, Y.R., Park, W.G., Park, O.H. Pollution Dispersion Analysis Usin the Puff Model With Numerical Flow Field Data, Mechanics Research Communications, 30, 4, 277-286, (2003).

[31] Konda, U. Singh, T. Singla, P. Scott P., Uncertainty Propagation in Puff Based Dispersion Models Using Polynomial Chaos, Environmental Modelling and Software, 25,12, 1608-1618 (2009). 
[32] Yuguo L., Evaluation of AERMOD and CALPUFF Air Dispersion Models for Livestock Odour Dispersion Simulation. Thesis Submitted to the College of Graduate Studies and Research in Partial Fulfillment of the Requirements for the Degree of Master Science in the Department of Agricultural and Bioresource Engineering University of Saskatchewan, Saskatoon, (2009).

[33] Demirarslan, K.O., Doğruparmak, Ş.Ç. Determining Performance and Application of Steady-State Models and Lagrangian Puff Model for Environmental Assessment of $\mathrm{CO}$ and NOx Emissions, Polish Journal of Environmental Studies, 25(1), 83-96, (2016).

[34] Demirarslan, K.O., Doğruparmak, Ş.Ç., Karademir, A. Evaluation of three pollutant dispersion models for the environmental assessment of a district in Kocaeli, Turkey, Global NEST Journal, 19(1), 37-48, (2017).

[35] Joneidi, N., Rashidi, Y., Atabi, F., Broomandi, P. Modeling of Air Pollutants' Dispersion by Means of CALMET/CALPUFF (Case Study: District 7 in Tehran city), Pollution, 4(2), 349-357, (2018).

[36] Sagan, V., Pasken, R., Zarauz, J., Krotkov, N. SO2 trajectories in a complex terrain environment using CALPUFF dispersion model, OMI and MODIS data, International Journal of Applied Earth Observation and Geoinformation, 69, 99-109, (2018).

[37] Leone, V., Cervone, G., Iovino, P. Impact assessment of PM10 cement plants emissions on urban air quality using the SCIPUFF dispersion model, Environ Monit Assess, 188(499) 1-12, (2016).

[38] Conan, O., Smith, K., Organo, C., Solier, L., Maro, D., Hebert, D. Comparison of RIMPUFF, HYSPLIT, ADMS atmospheric dispersion model outputs, using emergency response procedures, with $85 \mathrm{Kr}$ measurements made in the vicinity of nuclear reprocessing plant, Journal of Environmental Radioactivity, 124, 266-277, (2013). 